\title{
Irritable bowel syndrome among medical students and its association with anxiety.
}

1. MBBS, FCPS

Assistant Professor Medicine

Bahria University Medical Dental College.

2. MBBS, M.Phil

Professor Pathology

Bahria University Medical Dental College.

3. MBBS, M.Phil

Assistant Professor Pathology

Bahria University Medical Dental College.

4. MBBS, M.Phil

Assistant Professor Anatomy

Bahria University Medical Dental

College.

Correspondence Address:

Dr. Sehrish Shafique

Department of Medicine

Bahria University Medical Dental

College.

drsehrish80@yahoo.com

Article received on:

05/01/2021

Accepted for publication:

$10 / 03 / 2021$

\begin{abstract}
Sehrish Shafique ${ }^{1}$, Naveed Faraz ${ }^{2}$, Hina Wasti ${ }^{3}$, Ambreen Surti $^{4}$
\end{abstract}
ABSTRACT... Objective: To find out the frequency of Bowel Syndrome (IBS) among medical students according to ROME 111 criteria. To find out the frequency of common subtypes of IBS among the IBS positive medical students. To observe the association between anxiety, depression, and irritable bowel syndrome according to HAD scale. Study Design: Cross Sectional study. Setting: Medical Students of BUMDC. Period: September to November 2020. Material \& Methods: The study was conducted among the medical students at a private medical college in Karachi. Ethical approval taken. After taking consent questionnaires were given. The total students with irritable bowel syndrome were presented by their frequencies, then finding were analyzed using ROME 111 and HAD scale. Results: A total of 370 students were included after considering inclusion and exclusion criteria. Out of which 152 students $(41 \%)$ were found to have irritable bowel syndrome according to ROME 111 criteria. The most common IBS subtypes seen in our study was IBS -D (diarrhea) 80 . Among those students diagnosed with IBS, anxiety was positive in 100 students while depression was seen in 5 students according to HAD scale. Conclusion: This study concludes that medical students are more prone to develop IBS which is aggravated by stress related anxiety for having extensive curriculum and pressure from the peers of having good score in exam among intellectual section of the society which is not an easy task to cope up.

Key words: $\quad$ Anxiety, Depression, Diarrhea, Irritable Bowel Syndrome, Medical Students.

Article Citation: Shafique S, Faraz N, Wasti H, Surti A. Irritable bowel syndrome among medical students and its association with anxiety. Professional Med J 2021; 28(11):1561-1565. https://doi.org/10.29309/TPMJ/2021.28.11.6326

\section{INTRODUCTION}

IBS is a prevalent GIT condition, accounting for 20$50 \%$ referrals to gastro clinics. ${ }^{1}$ The prevalence of the disease worldwide ranges between $5.7-34 \%$. It is high among the Western population from 10 to $15 \%$ than Asian ones from 1 to $10 \%$. The exact prevalence of IBS in Pakistani population is unknown. ${ }^{2}$ However, a study was conducted in past among the college students which showed $34 \%$ prevalence. ${ }^{3}$ It is a condition in which the patient presented with diffuse abdominal pain, which is relieved by defecation, abdominal distension and change in the frequency of intestinal habits without any biochemical or organic cause. ${ }^{4}$ Diagnosis of irritable bowel syndrome is on the basis of Rome III criteria, which comprise of certain bowel symptoms like frequency and duration of bowel movements. ${ }^{5}$ According to ROME111 criteria Irritable bowel syndrome is defined as recurrent abdominal pain or discomfort for at least 3 days per month during last 3 months associated with two or more of the following features:

1. Improvement with defecation. And/or

2. Onset associated with a change in frequency of stool. And/or

3. Onset associated with a change in form (appearance) of stool.

The sensitivity of this Criterion is $65 \%$ for the diagnosis of IBS. ${ }^{6}$

Diagnosis of IBS is also established through the exclusion of organic gastrointestinal disease. There are, three recognized subtypes of IBS (1) diarrhea-predominant, (2) constipationpredominant, and (3) alternating diarrhea and constipation. $^{7}$

The exact cause of IBS remains undefined. Currently, mentioned mechanisms include 
exaggerated visceral hypersensitivity, gastrointestinal motor disturbances, and abnormal regulation of serotonin, post infectious IBS, and bacterial overgrowth. In addition, the brain gut axis has been suggested. ${ }^{8}$ But in some cases, genetic role has also been documented. Results of past studies revealed that girls especially in their twenties are more prone than boys of having IBS. ${ }^{9,10}$ One of the major contributors to IBS is stress. ${ }^{11}$ In patients having IBS stress is one of the factors that increases the bowel movements. ${ }^{12}$

Medical education is one of the most challenging and the most stressful education, and this may predispose to high rates of IBS. ${ }^{13}$ Medical students are considered to remain under more stressful environment than other groups of the studying population due to heavy burden of tough studies, their long duration stressful academic environment and mental exhaustion due to numerous exams and clinical workloads ${ }^{14}$ Stress is not only physical it is also related to sleeplessness and also psychological as they have heavy burden of studies. Their living routine, and their dietary habits are also affected, the tough academic environment might be the reasons for high occurrence of irritable bowel syndrome in them. Many studies have been done to determine the prevalence of IBS among medical students, and different ways of managing these patients. In order to improve their quality of life, different ways can be taken to help them physically, and psychologically. ${ }^{15}$ Occurrence of IBS can compromise their quality of life also as students can have problem in focusing on their studies. The role of stress can partly justify the high prevalence of IBS seen among medical students. So, the rationale of this study is to determine the frequency of Irritable bowel syndrome among the medical students in Pakistan, to determine the frequency of IBS subtypes and to determine its association with anxiety and stress.

\section{MATERIALS \& METHODS}

Study was conducted among MBBS and BDS students at a private medical college in Karachi during a period of 3 months. The study was commenced after the ethical approval taken from the ethical committee of BUMDC in September to November 2020. Medical student both /male and female with their age from 18 to 25 years were included in the study. Random sampling technique is used. Participants with diagnosed inflammatory bowel diseases, individuals with marked weight loss that is $10 \mathrm{lb}$. or more or $5 \%$ of the weight loss over a period of 6 months, any malignancy and known psychiatric illness were excluded from the study.

Those subjects who fulfilled the inclusion criteria were selected. The aim of the study and the contents of the questionnaire were explained to each subject and voluntary participation was requested. Consent was taken from the students prior to data collection. Those participants between 18-25 years of age irrespective of gender were included. They were given a questionnaire to fill in which they identified their gastrointestinal symptoms of IBS given according to ROME 111 criteria. Those found positive for having IBS were then given another questionnaire in which they identified their symptoms of anxiety and depression according to HAD scale.

\section{RESULTS}

Total students: 370

IBS positive students: 152

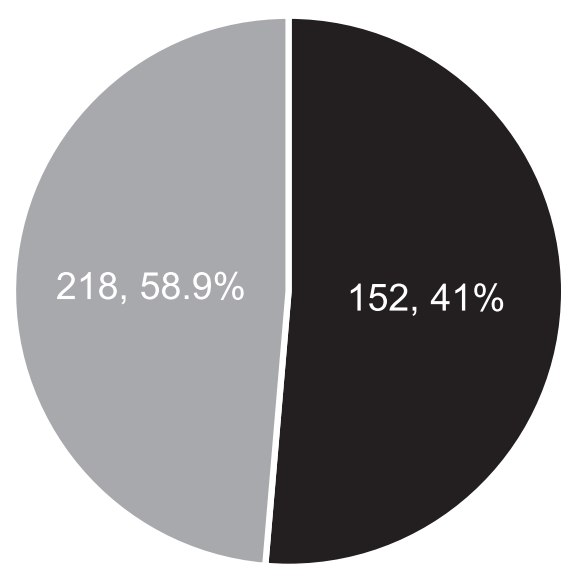

$\square$ IBS $\square$ NO IBS

Figure-1. Frequency of Bowel Syndrome (IBS) among medical students according to ROME 111 criteria. 


\begin{tabular}{|c|c|c|}
\hline Ibs Subtype & Total Ibs (152) & $\%$ of Subtype \\
\hline IBS Diarrhea & 80 & $52.6 \%$ \\
\hline IBS Constipation & 20 & $13 \%$ \\
\hline IBS Mixed & 50 & $32.8 \%$ \\
\hline IBS U & 2 & $1 \%$ \\
\hline \multicolumn{3}{|c|}{$\begin{array}{l}\text { Table-I. Frequency of common subtypes of IBS } \\
\text { among the IBS positive medical students. }\end{array}$} \\
\hline $\begin{array}{l}\text { Anxiety Among } \\
\text { IBS Patient }\end{array}$ & $\begin{array}{l}\text { Number of } \\
\text { Patients }\end{array}$ & $\begin{array}{l}\% \text { of Patient } \\
\text { Among IBS }\end{array}$ \\
\hline Mild(borderline) & 30 & $19.7 \%$ \\
\hline Severe (abnormal) & 80 & $52.6 \%$ \\
\hline Absent & 42 & \\
\hline \multicolumn{3}{|c|}{$\begin{array}{c}\text { Table-II. Anxiety and irritable bowel syndrome } \\
\text { according to HAD scale. }\end{array}$} \\
\hline $\begin{array}{l}\text { Depression } \\
\text { Among IBS Patient }\end{array}$ & $\begin{array}{l}\text { Number of } \\
\text { Patients }\end{array}$ & $\begin{array}{l}\% \text { of Patient } \\
\text { Among IBS }\end{array}$ \\
\hline Mild (borderline) & 3 & $2 \%$ \\
\hline Severe (abnormal) & 2 & $1.3 \%$ \\
\hline Absent & 148 & \\
\hline
\end{tabular}

\section{DISCUSSION}

In our study the 370 subjects were included among which 152 were found to have irritable bowel syndrome based on ROME 111 criteria that make $41 \%$ IBS among total 370 subjects as shown in figure-1. Our results are consistent with the Studies from Iran by Mansour-Ghanaei $\mathrm{F}^{16}$, and from Bangladesh by Masud $\mathrm{MA}^{17}$, which found $37.7 \%$ and $35 \%$ of IBS cases among the medical students. Whereas our result is different from the studies done in Japan by Okami $Y$ etal. ${ }^{18}$ Elhosseiny D etal ${ }^{19}, 31 \%$ by Qureshi et al in Saudi Arabia $^{20}$ but the previous studies done in Pakistan by, Naeem SS. etal ${ }^{21}$ and Jafri Wetal showed $28.3 \%$ prevalence of IBS among the medical students. ${ }^{22}$ These differences in the frequency could be due to variation in cultural, ethical, and dietary habits of different countries. In this study we have determined the frequency of different subtypes of Irritable bowel syndrome. Our observation also showed that IBS-D (diarrhea) was more common $80(52.6 \%)$ among the medical students then other subtypes. As shown in Table-I. This is consistent with previous study by Nagasako $\mathrm{CK}^{23}$ but in another study by Elhosseiny $D$ et.al conclude constipation remained predominant subtype. Also, in another study by Naeem SS etal.in which IBS-Mixed subtype remained predominant which in our study remained second highest among are subjects 50 (32.8\%).

In another finding in our study subjects having, IBS positive with anxiety present in 100 students which is $65.7 \%$ among total IBS positive student as shown in Table-II. Based on HAD scale we have determined that those students who had IBS had severe anxiety 80 student (52.6\%) as compared to borderline anxiety 30 student (19.7\%). This result showed that in medical students' severe anxiety is more prevalent which can be one of the aggravating factors for the occurrence of IBS in them. This finding is consistent with studies done by Al-Turki et al ${ }^{24}$ Elhosseiny D etal, Naeem SS et al, Blanchard et $\mathrm{al}^{25}$ and Surdea-Blaga et $\mathrm{al}^{26}$ all studies emphasize that stressful life events can exacerbate GIT symptoms. But there was a study done by Farzaneh et $\mathrm{al}^{27}$ that found no significant difference in the psychological association between anxiety and IBS. In our study depression was seen in only 5 subjects (3\%) as shown in Table-III. The anxiety among medical students is mainly due to the heavy burden of tough studies and stress of achieving good grades in their medical years. This shows that other than lifestyle and dietary factors anxiety and stress have impact on bowel habits and can alter them resulting in IBS.

\section{LIMITATION}

The main limitation of the study is the limitation sample size; this study can further be conducted on large scale In future and comparison studies with other colleges can also be done.

\section{CONCLUSION}

This study concludes that medical students are more prone to develop IBS which is aggravated by stress related anxiety for having extensive curriculum and pressure from the peers of having good score in exam among intellectual section of the society which is not an easy task to cope up. Copyright $\odot 10$ Mar, 2021. 


\section{REFERENCES}

1. Jafri W, Jafri YN, Maloni M, Hamid S, Shah HA, Abid S. Irritable bowel syndrome in health care professionals in Pakistan. Journal of Pakistan Medical Association JPMA 2003; 53(9):405-407.

2. Mohameda N, Khaled H, Abdullah C K, Ramadand N, Alzuhairie R, Alqurashif R . Irritable bowel syndrome among female students in princess nourah university in kingdom of Saudi Arabia. Sciences: Basic and Applied International Journal of Sciences: Basic and Applied Research (IJSBAR). 2019; 43 (1): 197-205.

3. Ibrahim NK. A systematic review of the prevalence and risk factors of irritable bowel syndrome among medical students. Turk J Gastroenterol 2016; 27: 10-6. DOI: 10.5152/tjg.2015.150333.

4. Saito Y, Schoenfeld P, Locke G III. The epidemiology of irritable bowel syndrome in North America: A systematic review 1. Am J Gastroenterol 2002; 97(8):1910-5. DOI: 10.1111/j.1572-0241.2002.05913.x.

5. Stojanovic MR, Jonkers DM, Salonen A, et al. Intestinal micobiota and diet in IBS; causes, consequences or epiphenomena? The American journal of Gasteroenterolgy. 2015; 110(2)278-87. DOI: 10.1038/ ajg.2014.427.

6. Hasosah MY, Alamri SA, Al-Husayni F, Aljedaani R, Zwawy MA, Zahrani $A$. The prevalence of irritable bowel syndrome among medical students and interns in Jeddah, Saudi Arabia. EC Gastroenterology and Digestive System 2017; 87-93.

7. AL Aqeel MK, Alowaimer NA, Alonezan AF, Almegbel NY, Alaujan FY. Prevalence of irritable bowel syndrome and its association with anxiety among medical students at King Saud bin Abdulaziz University for Health Sciences in Riyadh. Pak J Med Sci. 2017; 33(1):33-36. doi: https://doi.org/10.12669/ pjms.331.12572.

8. Butt AS. Salih M, Jafri W, Yakoob J, Wasey M, Hamid S. Irritable bowel syndrome and psychiatric disorders in Pakistan: A case control study hindawi publishing corporation gastroenterology research and practice. 2012 .doi:10.1155/2012/291452, Article ID 291452.

9. Al-Butaysh OF, Al-Quraini AA, A-Imukhaitah AA, Alahmdi YM, Al-harbi FS. Epidemiology of irritable bowel syndrome and its associated factors in Saudi undergraduate students. Journal of the Saudi Gastroenterology Association, 01 Mar 2020, 26(2):8993 DOI: 10.4103/sjg.sjg_459_19.
10. Qin HY, Cheng CW, Tang XD, Bian ZX. Impact of psychological stress on irritable bowel syndrome. World journal of gasteroenterology. 2014; 20(39): 14126-31. doi: 10.3748/wjg.v20.i39.14126.

11. Al-bukhari I, Al-Malki K, Kashkari M, Alrifai M, Adnan $M$. Prevalence and factors affecting irritable bowel syndrome among medical students at Taibah University. Clinical Medicine Research. 2016; 5(1):1-5. doi: 10.11648/j.cmr.20160501.11.

12. Ibrahim NKR, Battarjee WF, Almehmadi SA. Prevalence and predictors of irritable bowel syndrome among medical students and interns in King Abdulaziz University, Jeddah. Libyan Journal of Medicine 2013 Sep 19; 8:21287.doi: 10.3402/jjm.v8i0.21287.

13. C Ford AC, Lacy BE, Talley NJ. Irritable bowel syndrome. N Engl J Med. 2017 Jun 29; 376(26):25662578. doi: 10.1056/NEJMra1607547.

14. Lacy BE, Patel NK. Rome criteria and a diagnostic approach to irritable bowel syndrome. J Clin Med. 2017 Nov; 6(11): 99. doi: 10.3390/jcm6110099.

15. Heidelbaugh JJ, Stelwagon M, Miller SA, Shea EP, Chey WD. The spectrum of constipation-predominant irritable bowel syndrome and chronic idiopathic constipation: US survey assessing symptoms, care seeking, and disease burden. Am J Gastroenterol. 2015; 110(4):580-587. doi: 10.1038/ajg.2015.67.

16. Masud MA, Hasan M, Khan AK. Irritable bowel syndrome in a rural community in Bangladesh: Prevalence, symptoms pattern, and health care seeking behavior. Am J Gastroenterol. 2001; 96: 154752. DOI: 10.1111/j.1572-0241.2001.03760.x.

17. Mansour-Ghanaei F, Fallah MS, Heidarzadeh A, Jafarshad R, Joukar F, Rezvan-Ghasemipour, et al. Prevalence and characteristics of irritable bowel syndrome (IBS) amongst medical students of Gilan Northern Province of Iran. MEJDD. 2011; 1: 1005.

18. Okami Y, Kato T, Nin G, Harada K, Aoi W, Wada S, et al. Lifestyle and psychological factors related to irritable bowel syndrome in nursing and medical school students. J Gastroenterol. 2011 Dec; 46(12):1403-10. doi: 10.1007/s00535-011-0454-2. Epub 2011 Aug 24. DOI: 10.1007/s00535-011-0454-2.

19. Elhosseiny D, Mahmoud N, Manzour A. Factors associated with irritable bowel syndrome among medical students at Ain Shams University. Journal of the Egyptian Public Health Association. 2019; 94:23. DOI: 10.1186/s42506-019-0023-8. 
20. Qureshi SR, Abdelaal AM, Janjua ZA, Alasmari HA, ObadAS. Irritable bowel syndrome: A global challenge among medical students. Cureus 2016.; 8(8). DOI: 10.7759/cureus.721.

21. Naeem SS, Siddiqui EU, Kazi AN, Memon AA, Khan ST, Ahmed $B$. Prevalence and factors associated with irritable bowel syndrome among medical students of Karachi, Pakistan: A cross-sectional study. BMC Res Notes. 2012; 5: 255. DOI: 10.1186/1756-0500-5-255.

22. Jafri W, Yakoob J, Jafri N, Islam M, Ali QM. Frequency of irritable bowel syndrome in college students. $J$ Ayub Med Coll Abbottabad. 2005; 17: 911.

23. Nagasako CK, Montes CG, Silva-Lorena SLan, Maria, Mesquita A. Irritable bowel syndrome subtypes: Clinical and psychological features, body mass index and comorbidities. Revista espanola de enfermedades digestivas: organo oficial de la Sociedad Espanola de Patologia Digestiva Rev Esp Enferm Dig. 2016 Feb; 108(2):59-64.doi: 10.17235/ reed.2015.3979/2015.
24. Al-Turki Y, Aljulifi YA, Al Murayshid A, Al Omaish HR, Al Daghiri KS, Al Seleemi AY, et al. Prevalence of irritable bowel syndrome among students in king Saud University, Riyadh, Saudi Arabia. World Fam Med J. 2011; 9: 17-20. DOI:10.5742/MEJFM.2011.95002.

25. Blanchard EB, Lackner JM, Jaccard J, Rowell D, Carosella AM, Powell C, Sanders K, Krasner S, Kuhn E. The role of stress in symptom exacerbation among IBS patients. J Psychosom Res 2008; 64: 119-128 [PMID: 18222125 DOI: 10.1016/ j. jpsychores.2007.10.010].

26. Surdea-Blaga T, Băban A, Dumitrascu DL. Psychosocial determinants of irritable bowel syndrome. World $\mathrm{J}$ Gastroenterol 2012; 18: 616-626 [PMID: 22363132 DOI: 10.3748/wjg. v18.i7.616].

27. Farzaneh N, Ghobakhlou M, Moghimi-Dehkordi B, Naderi N, Fadai F. Evaluation of psychological aspects among subtypes of irritable bowel syndrome. Indian J Psychol Med 2012; 34: 144-148 [PMID: 23162190 DOI: $10.4103 / 0253-7176.101780]$.

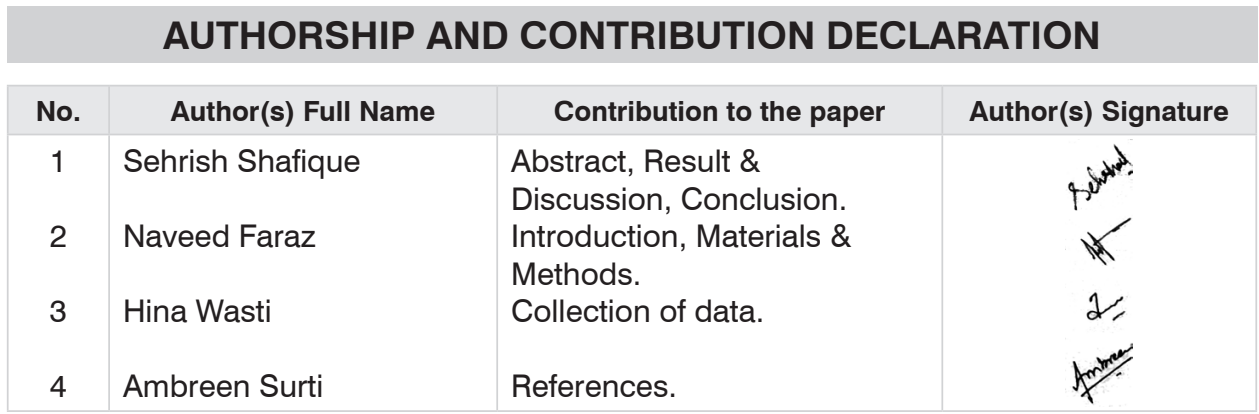

